\title{
US broadens scientific base of controls on carcinogens
}

Washington. The US Environmental Protection Agency (EPA) this week unveiled the first revisions to its guidelines for determining human cancer risk in ten years. The long-awaited guidelines will allow more flexibility in regulating carcinogens, and will ensure that "cancer risk assessments reflect the very best scientific knowledge available", according to Carol Browner, the EPA administrator.

In doing so, the new guidelines in effect shift decision-making away from scientists and toward 'risk managers'. But some environmentalists fear that they will also lead to more ambiguous risk assessments, and make it more difficult to regulate suspected carcinogens. "From a public policy standpoint, we are extremely disappointed," says Al Meyerhoff of the Natural Resources Defense Council (NRDC). He calls the new guidelines "an invitation to torpor, delay and foot-dragging".

Traditionally, EPA has relied heavily on rodent bioassays to establish whether a particular agent causes cancer. Rats are given a chemical, and then watched for two years to see if tumours develop. In contrast, the new guidelines call for using a wider range of information, including genetic data, information on the agent's physical and chemical structure, and testing for biological effects leading up to tumour development.

EPA has been making increasing use of these other techniques in recent years to assess cancer risk. But they often have been a "secondary thought" says Jeanette Wiltse of the agency's National Center for Environmental Assessment in Washington.

Under the revised guidelines, EPA will drop its long-standing scheme for classifying cancer hazards by assigning each substance to one of six categories, starting with Category $\mathrm{A}$ for known human carcinogens. Instead, the agent will be classified according to one of three 'descriptors' of its human carcinogenic potential: 'known/likely', 'cannot be determined', and 'not likely'.

Each substance also will receive a narrative description of its potential to cause cancer under different conditions, as well as a short summary of the animal and human evidence supporting these conclusions. These 'weight of evidence' narratives are meant to give risk managers more information than just a simple category designation, says Wiltse. They will also allow risk assessors "to express things they hadn't been expressing when they had to boil [the classification] down to a letter".

Gone, too, is EPA's previous assumption that all dose-response relationships are strictly linear. Risk assessors may now use non-linear approaches to estimating toxic effects at low doses, which could lead to known carcinogens being declared safe below a certain threshold. The new guidelines also allow risk assessors to consider different exposure routes - for example, inhalation versus ingestion - as well as effects on different populations, such as children and pregnant women.

The proposed new guidelines closely follow recommendations from a 1994 National Research Council (NRC) study Science and Judgment in Risk Assessment, and the initial reaction to EPA's announcement among scientists has generally been favourable. Ronald Estabrook of the University of Texas Southwestern Medical Center in Dallas, for example, who chaired a recent NRC study of carcinogens in food, calls the added flexibility "a very positive move".

Roger McLellan of the Chemical Industry Institute of Toxicology in North Carolina says that he particularly supports EPA's shift from a single category designation to a narrative description of cancer hazards. This, he says, "recognizes that chemicals can cause cancer in different ways" and gets away from the "tyranny of lists".

But Meyerhoff says his organization opposes the shift away from "the bright red line we've had in the past" to differentiate between "known" and "probable" carcinogens, and adds that NRDC will seek to retain the old category system. He also says that the guidelines, in their increased reliance on new types of information, overstate the ability of scientists to understand the causes of cancer. "I fear we're seeing scientific hubris here," he says. "These guidelines assume far more certainty about carcinogenesis than actually exists."

EPA says it plans to continue using use existing cancer assessments until revised assessments based on new data are completed and have been peer-reviewed. That raises another fear among environmentalists - that chemical manufacturers will flood the agency with requests to reassess any substances now labelled carcinogenic, and paralyze the process as a result.

But Wiltse says that in some cases, new techniques can speed up the process, particularly when risk assessors do not have to wait for two-year rat tumour studies to be completed. Substances that already have a large database and an advanced risk assessment will move more quickly through the reassessment process, she says.

The proposed guidelines are being published in the Federal Register this week, and have been posted on the World Wide Web at http://www.epa.gov/ORD/WebPubs/carcinogen. The public will have four months to comment.

Tony Reichhardt

\section{IMAGE UNAVAILABLE FOR COPYRIGHT REASONS}

Yeltsin: reaching out for scientists' votes.

\section{Yeltsin promises more money for science}

Moscow. President Boris Yeltsin, currently campaigning for re-election, last week signed a decree promising the Russian Academy of Science a budget next year that is 50 per cent higher than this year's, granting additional tax privileges to the academy, and allocating 50 billion rubles (US\$10 million) a year over the next five years for the construction of apartments for young scientists.

The barely concealed political motivation behind the move became even more obvious the following day, when Yeltsin made a speech in which he said he relied strongly on scientists and was eager to support them. "Only science and education can prevent a political and social Chernobyl, since the chain reaction of the former regime's disintegration has not yet been stopped," he said.

Yeltsin was taking part in centenary anniversary celebrations for Nikolai Semenov, the first Soviet winner of the Nobel prize in 1956 for his study of chemical reactions, held in the Grand Hall of Columns in Moscow.

The prime minister, Viktor Chernomyrdin, presided over the meeting, which was also attended by Federico Mayor, the director general of the United Nations Educational, Scientific and Cultural Organization (Unesco).

Also present were deputy prime minister Oleg Soskovets, Evgeny Primakov, the foreign affairs minister, Yuri Luzhkov, the mayor of Moscow, and Yuri Osipov, president of the academy. Their combined presence at a scientific gathering, virtually without precedence in the past few decades, was seen as a clear signal to the scientific community that Yeltsin and his supporters are seeking their support in the coming presidential elections.

Mayor told the Russian officials present that he was certain that the contribution of Russian scientists to world science "will be proportional to Russia's contribution to international cooperation" - a comment which was seen by some as an indirect reference to the fact that Russia still owes money to Unesco, although others claimed that it was merely a standard piece of public rhetoric.

Carl Levitin 